\title{
DIFFERENCES OF APOLIPOPROTEIN A1 AND APOLIPOPROTEIN B LEVELS IN TYPE 2 DIABETES MELLITUS (T2DM) PATIENTS WITH DIABETIC RETINOPATHY AND WITHOUT DIABETIC RETINOPATHY
}

\author{
Shabrina Hanifah ${ }^{1}$, Indra Tri Mahayana ${ }^{1 *}$, Suhardjo ${ }^{1}$, Angela Nurini Agni ${ }^{1}$, Teguh Triyono ${ }^{2}$ \\ ${ }^{1}$ Department of Ophthalmology, Faculty of Medicine, Public Health, and Nursing, Universitas Gadjah Mada- \\ Dr. Sardjito General Hospital, Yogyakarta, Indonesia \\ ${ }^{2}$ Department of Clinical Pathology, Faculty of Medicine, Public Health, and Nursing, Universitas Gadjah Mada- \\ Dr. Sardjito GeneralHospital, Yogyakarta, Indonesia
}

\begin{abstract}
Introduction: Apolipoprotein A1 is antiatherogenic in blood serum and has an anti-inflammatory effect in blood serum while apolipoprotein $B$ is potentially atherogenic. Diabetic retinopathy occurs due to the inflammation process. Apolipoprotein A1 plays a role as a protector in the case of diabetic retinoplathy. This study aimed to determine whether there were differences in the levels of apolipoprotein $A 1$ and $B$ in diabetic retinopathy patients and without diabetic retinopathy.
\end{abstract}

Methods: This study used a cross-sectional design. This study's subjects were T2DM patients with diabetic retinopathy and without diabetic retinopathy at Dr. Sardjito General Hospital (Yogyakarta, Indonesia) from July to September 2020. Subjects consisted of 32 patients with diabetic retinopathy and 31 patients without diabetic retinopathy. The levels of apolipoprotein A1 and apolipoprotein B were analyzed using an independent T-test. The factors affecting apolipoprotein $A 1$ and apolipoprotein $B$ were examined using multiple regression tests.

Result: There were no significant differences ( $p>0.05$ ) in age, gender, duration of diabetes, HDL, triglycerides, $\mathrm{HbA1C}, \mathrm{BMI}$, physical activity, and smoking history. The mean apolipoprotein A1 level in the diabetic retinopathy group was $1.46 \pm 0.177 \mathrm{mg} / \mathrm{dL}$ higher than the non-diabetic retinopathy group, which was $1.44 \pm 0.27 \mathrm{mg} / \mathrm{dL}(p=0.699)$. The mean level of apolipoprotein $B$ in the diabetic retinopathy group was $1.26 \pm 0.289 \mathrm{mg} / \mathrm{dl}$ higher than the non-diabetic retinopathy group of 1.01 $\pm 0.26 \mathrm{mg} / \mathrm{dL}(p=0.001)$. The mean LDL levels were $162.5 \pm 48.38 \mathrm{mmol} / \mathrm{L}$ in the diabetic retinopathy group and $127 \pm 38.45 \mathrm{mmol} / \mathrm{L}$ in the group without diabetic retinopathy $(p=0.012)$

Conclusion: Apolipoprotein B levels were found to be higher in T2DM patients with diabetic retinopathy than in those without diabetic retinopathy. There was a significant difference between the two assumed due to an atherogenic process in the diabetic retinopathy group. Further research is needed to assess the causal relationship between elevated levels of Apolipoprotein $B$ and the incidence of diabetic retinopathy by calculating the ratio of apolipoprotein B to apolipoprotein A1.

\footnotetext{
Keywords: intravitreal, macular edema, pharmacotherapy, vein occlusion, vitreous detachment Cite This Article: HANIFAH, shabrina. Differences in Levels of Apolipoprotein A1 and Apolipoprotein B in Patients Diabetes Mellitus Type 2 with Diabetic Retinopathy and Without Diabetic Retinopathy. International Journal of Retina, [S.I.], v. 4, n. 2, p. 93, sep. 2021. ISSN 2614-8536. Available at: <https://www.ijretina.com/index.php/ijretina/article/view/153>.doi: https://doi.org/10.35479/ijretina.2021.v ol004.iss002.153.
}

Correspondence to:
Shabrina Hanifah,
Dr. Sardjito General Hospital,
Yogyakarta, Indonesia,
shab.hanifah@gmail.com

\section{INTRODUCTION}

Diabetic retinopathy is the most common microvascular disease. It can cause blindness and vision problems in the world. 
The likelihood of retinal disease increases with the duration of diabetes and will become one of the causes of blindness for more than 10,000 people with diabetes mellitus per year. ${ }^{(1)}$ In patients with diabetes mellitus, hyperglycemia occurs and causes microangiopathy. Microangiopathy may result in vascular leakage, which leads to diabetic macular edema and capillary occlusion. Capillary occlusion causes retinal ischemia and increased levels of vascular endothelial growth factor (VEGF), which is responsible for the development of neovascularization and the proliferative stage of diabetic retinopathy. ${ }^{(2)}$

Developing countries such as Australia and New Zealand have a lower prevalence of T2DM than other developing countries. Also, another study stated that Asian patients had higher postprandial blood sugar than Caucasians. Almost all Asian countries have different nutritional transitions with increased carbohydrates, animal fats and meat, and less fiber and vegetables. Diets in South Asia are characterized by a high intake of carbohydrates, trans fats, and saturated fats, so that there is a risk of T2DM ${ }^{(3)}$ From several studies, it is stated that apolipoproteins are more influential in diabetic retinopathy's appearance compared to traditional fatty serum such as $\mathrm{HDL}$, LDL, and VLDL ${ }^{(4-6)}$ From WESDR XIII reported that cholesterol levels were not related to the severity of either ocular condition in older-onset patients. HDL$C$ was unrelated to the severity of either lesion. Totalto-HDL cholesterol ratio and LDL-C could predict the development of CSME and hard exudate. Higher serum lipids were associated with an increased risk of CSME and retinal hard exudate. ${ }^{(7)}$ Although apolipoprotein $\mathrm{A} 1$ is associated with $\mathrm{HDL}$ and apolipoprotein $B$ is associated with $L D L$, it does not mean that $\mathrm{HDL}$ and $\mathrm{LDL}$ have the same relationship with diabetic retinopathy. There are several reasons to explain this. First, apolipoproteins reflect protein binding with structure, enzymes, and function as receptors, while HDL cholesterol and LDL cholesterol only reflect $\mathrm{HDL}$ and $\mathrm{LDL}$ cholesterol's fat content. HDL contains several apolipoprotein A1 molecules while LDL, VLDL, IDL only contains one apolipoprotein B molecule. Second, patients with DM induce several changes, such as glycation, oxidation, and modification of the advanced glycation end products of lipoproteins. In contrast, apolipoprotein A1 and apolipoprotein B levels are more stable than traditional serum fat because they are not affected by prandial status. ${ }^{(4,6)}$ The retina has a protective mechanism through apoA 1 to fight lipid and lipotoxin deposits that induce inflammation resulting in diabetic retinopathy. ApoA 1 has antiinflammatory and antioxidant effects and is key to intraretinallipid transport. If the level of apoA 1 is low, it will accelerate the occurrence of diabetic retinopathy. ${ }^{(8)}$ This study aims to determine whether there were differences in the levels of apolipoprotein $A 1$ and $B$ in diabetic retinopathy patients and without diabetic retinopathy.

\section{METHODS}

The research employed a cross-sectional study and conducted at Dr. Sardjito General Hospital in July to September 2020. The research subjects were T2DM sufferers with diabetic retinopathy and without diabetic retinopathy.

Patients who were included in the study criteria were carried out anamnesis regarding the length of suffering from T2DM, history of smoking, history of dyslipidemia treatment, history of aerobic physical activity, physical and ophthalmological examinations. The clinical laboratory took blood for the examination of $\mathrm{HDL}, \mathrm{LDL}$, triglycerides, $\mathrm{HbA} 1 \mathrm{c}$, apolipoprotein A1, and apolipoprotein B. Physical activity is defined as any bodily movement by skeletal muscle that requires energy expenditure. Still, in this study we didn't count the intensity. The inclusion criteria were T2DM patients with diabetic retinopathy and without diabetic retinopathy, willing to attend the study, 
not currently pregnant, not being treated for dyslipidemia, and no history of hereditary lipid disorders. The exclusion criteria were samples that did not meet the requirements such as lysis.

The collected data were then processed using SPSS. All data were tested for normality with the

Table 1. Demographic and Clinical Characteristic Subjects

\begin{tabular}{|c|c|c|c|}
\hline Variable & $\begin{array}{c}\text { Diabetic } \\
\text { Retinopathy } \\
(n=32)\end{array}$ & $\begin{array}{c}\text { Non diabetic } \\
\text { retinopathy } \\
(n=31)\end{array}$ & $P$ \\
\hline Age (years) & $54,5 \pm 6,72$ & $57,35 \pm 7,48$ & 0,134 \\
\hline Gender(\%) & & & 0,367 \\
\hline Male & $16(50 \%)$ & $19(61,3 \%)$ & \\
\hline Female & $16(50 \%)$ & $12(38,7 \%)$ & \\
\hline $\begin{array}{l}\text { Visual acuity OD } \\
\text { (logmar) }\end{array}$ & $0,89 \pm 0,59$ & $0,68 \pm 0,54$ & 0,00 \\
\hline $\begin{array}{l}\text { Visual acuity OS } \\
\text { (logmar) }\end{array}$ & $0,86 \pm 0,55$ & $0,79 \pm 0,65$ & 0,297 \\
\hline DME (eyes) & & & 0,004 \\
\hline Yes & $11(23,4 \%)$ & $0 \%$ & \\
\hline No & $36(76,6 \%)$ & 31 (100\%) & \\
\hline Physical activity & & & 0,241 \\
\hline Yes & $16(50 \%)$ & $11(35,5 \%)$ & \\
\hline No & $16(50 \%)$ & $20(64,5 \%)$ & \\
\hline BMI (m/kg2) & $23,97 \pm 3,1$ & $24,28 \pm 3,47$ & 0,710 \\
\hline Smoking & & & 0,146 \\
\hline Yes & $7(21,9 \%)$ & $12(38,7 \%)$ & \\
\hline No & $24(78,1 \%)$ & $19(61,3 \%)$ & \\
\hline $\begin{array}{l}\text { Duration of DM } \\
\text { (years) }\end{array}$ & $9,75 \pm 5,68$ & $8,06 \pm 5,507$ & 0,167 \\
\hline $\begin{array}{l}\text { HDLcholesterol } \\
\text { (mmol/L) }\end{array}$ & $46,25 \pm 9,84$ & $49,06 \pm 16,47$ & 0,512 \\
\hline $\begin{array}{l}\text { LDLcholesterol } \\
\text { (mmol/L) }\end{array}$ & $162,5 \pm 48,38$ & $127 \pm 38,45$ & 0,012 \\
\hline Trigliserida & 239,46 & $255 \pm 227,09$ & 0,929 \\
\hline$(\mathrm{mmol} / \mathrm{L})$ & 181,54 & & \\
\hline HbA1c (\%) & $8,94 \pm 2,50$ & $8,70 \pm 2,2$ & 0,690 \\
\hline Apo A1 (mg/dL) & $1,46 \pm 0,177$ & $1,44 \pm 0,27$ & 0,699 \\
\hline Apo B (mg/dL) & $1,26 \pm 0,289$ & $1,01 \pm 0,26$ & 0,001 \\
\hline
\end{tabular}

Kolmogorov test to determine whether the data distribution was normal or not. Normally distributed data such as body mass index (BMI), apolipoprotein $A 1$, and apolipoprotein B were then analyzed using unpaired T-test while not-normally distributed data were analyzed using Mann Whitney. Multiple linear regression tests were used to analyzed the factors that influence apolipoprotein A1 and apolipoprotein B.

\section{RESULTS}

The mean age in the diabetic retinopathy group was not significantly different from the non-diabetic retinopathy group $(54.5 \pm 6.72$ vs $57.35 \pm 7.48$, $p=$ $0.134)$. This study found demographic and clinical characteristic subjects as follows(Table 1).

Table 2. Mean Levels of Apolipoprotein A1 and Apolipoprotein B According to Severity of Diabetic Retinopathy

\begin{tabular}{|c|c|c|c|c|}
\hline $\begin{array}{c}\text { NPDR severe } \\
\text { ( } n=6 \text { eyes) }\end{array}$ & $\begin{array}{l}\text { PDR } \\
\text { early } \\
\text { ( } n=9 \\
\text { eyes) }\end{array}$ & $\begin{array}{c}\text { PDR } \\
\text { High } \\
\text { Risk } \\
\text { ( } n=20 \\
\text { eyes) }\end{array}$ & $\begin{array}{c}\text { PDR } \\
\text { advan } \\
\text { ced } \\
\text { ( } n=11 \\
\text { eyes) }\end{array}$ & $p$ \\
\hline $1,4 \pm 0,18$ & $\begin{array}{l}1,48 \pm 0, \\
23\end{array}$ & $\begin{array}{l}1,42 \pm 0 \\
17\end{array}$ & $\begin{array}{l}1,49 \pm \\
0,20\end{array}$ & $\begin{array}{l}0,31 \\
9\end{array}$ \\
\hline $0,90 \pm 0,22$ & $\begin{array}{l}1,23 \pm 0, \\
17\end{array}$ & $\begin{array}{l}1,29 \pm 0, \\
275\end{array}$ & $\begin{array}{l}1,10 \pm \\
0,307\end{array}$ & $\begin{array}{l}0,05 \\
8\end{array}$ \\
\hline $0,66 \pm 0,98$ & $\begin{array}{l}0,84 \pm 0, \\
168\end{array}$ & $\begin{array}{l}0,92 \pm 0, \\
22\end{array}$ & $\begin{array}{l}0,76 \pm \\
0,26\end{array}$ & $\begin{array}{l}0,08 \\
7\end{array}$ \\
\hline
\end{tabular}

Table 3. Correlation BetweenApolipoprotein A1 with Some Variables in Diabetic Retinopathy

\begin{tabular}{lll}
\hline Variables & $\begin{array}{l}\text { Correlation } \\
\text { Coefficient }\end{array}$ & $\mathrm{p}$ \\
\hline BMI & $-0,176$ & 0,168 \\
Age & $-0,155$ & 0,198 \\
Smoking & 0,489 & 0,002 \\
Physical activity & $-0,022$ & 0,43 \\
HDL cholesterol & 0,559 & $<0,001$ \\
LDL cholesterol & 0,029 & 0,437 \\
Trigliseride & $-0,159$ & 0,192 \\
\hline
\end{tabular}


Table 4. Correlation Between Apolipoprotein B with Some Variables in Diabetic Retinopathy

\begin{tabular}{llc}
\hline Variables & $\begin{array}{l}\text { Correlation } \\
\text { Coeffiecients }\end{array}$ & $\mathrm{p}$ \\
\hline BMI & 0,103 & 0,287 \\
Age & -0.179 & 0,164 \\
Smoking & -0.143 & 0,218 \\
Physical activity & 0.109 & 0,277 \\
HDI cholesterol & $-0,280$ & 0,060 \\
LDL cholesterol & 0,732 & $<0,001$ \\
Trigliseride & 0,393 & 0,013 \\
\hline
\end{tabular}

Tables 3 and 4 describe the correlation between apolipoprotein A1 and apolipoprotein B with several variables in diabetic retinopathy patients. $L D L$ cholesterol had a strong correlation with apolipoprotein B, while triglycerides had a weak correlation with apolipoprotein B. In this study, triglycerides were not significantly different between the two groups, while LDL cholesterol levels were significantly different. The results of the study were not influenced by triglycerides but by LDL levels. In this case, these variables do not affect the levels of apolipoprotein A1 and apolipoprotein B.

\section{DISCUSSION}

This study reveals that the levels of apolipoprotein A1 between the two groups were not significantly different, but significantly different in apolipoprotein B. It can be concluded that there is already an atherogenesis process in the diabetic retinopathy group. This result was similar to the study conducted by Namitha et al., according to which the levels of apolipoprotein A1 and apolipoprotein B were not significanty different between the groups with diabetic retinopathy and without diabetic retinopathy. However, the differenceis significant if the group of healthy patients (not suffering from DM) both with the diabetic retinopathy group and without diabetic retinopathy. ${ }^{(9)}$ Previous studies demonstrated that the highest significant results were apolipoprotein $A 1$ in healthy patients without T2DM followed by T2DM patients without diabetic retinopathy, NPDR, and the lowest result in the PDR group. Similar results were obtained in a study by
Sasongko et al, where apolipoprotein A1 levels decreased significantly in patients with diabetic retinopathy and with increasing severity of diabetic retinopathy $(p=0.001) \cdot{ }^{(4,10)}$ Another study stated that apolipoprotein $B$ had a positive correlation with the severity of diabetic retinopathy $(p \leq 0.001)$ while apolipoprotein $A$ negatively correlated with the severity of diabetic retinopathy $(p \leq 0.001){ }^{(6)}$

This study concluded that LDL and triglycerides affect apolipoprotein B levels in both patients with or without diabetic retinopathy. The levels of apolipoprotein A1 in the two groups did not differ significantly possibly because HDL levels were not statistically significant. Apolipoprotein A1 is the major structural protein in HDL. High levels of apolipoprotein $\mathrm{A} 1$ suggest a protective mechanism in the retina via apolipoprotein $\mathrm{A} 1$ against lipid deposits inflammation-inducing lipotoxicity that causes diabetic retinopathy. Increased levels of apolipoprotein B are associated with worsening of diabetic retinopathy according to severity. Moreover, high levels of apolipoprotein B lead to the production of the lipoproteins related totoxins that can damage retinal vascular cells. ${ }^{(11)}$

In this study, age and sex did not differ significantly between the two groups. This result was not much different from the study by Namitha et al. The mean age of the control group, the T2DM group without diabetic retinopathy, and the T2DM group with diabetic retinopathy were $50.43 \pm 11.74,52.97 \pm$ 12.46, and 56.16. \pm 7.93, and each was not statistically significant. In addition, the distribution of men and women in each group was not statistically significant. $\left.{ }^{(9)}\right)$. Similarly, Sharma et al. explained that there was no significant difference in the age and sex of the patient group with T2DM and the group of patients without T2DM ${ }^{(10)}$. The duration of Sharma et al.'s study was slightly longer in the diabetic retinopathy group, but still, both groups were not significantly different. This result is contrast to the study by Sharma et al., which stated that the duration 
of DM was significant with a mean of $7.5 \pm 4.7$ years in the group without diabetic retinopathy, $10 \pm 5.2$ years in the NPDR group, and $14.1 \pm 6.9$ years in the PDR group ( $p<0.001) .{ }^{(10)}$ Other studies also mention a significant relationship between the duration of T2DM and diabetic retinopathy, namely the prevalence of diabetic retinopathy 5 to $25 \%$ after 14 years of suffering from diabetes and $3.5 \%$ if it is less than 14 years $^{(12)}$

In this study, the BMI was not significantly different. In other studies, it is stated that BMI negatively correlates with retinopathy, while several studies have reported that $\mathrm{BMI}$ is a risk factor for retinopathy. However, several studies also found that $\mathrm{BMI}$ was not significant towards the occurrence of diabetic retinopathy. ${ }^{(13)}$ In addition, diabetic macular edema (DME) in this study did not differ significantly between the two groups. However, another study stated that the estimated prevalence of PDR was $41 \%$ in each patient, and $23.8 \%$ had macular edema. The estimated incidence of PDR was $1.21 \%$ annually, and $0.77 \%$ had macular edema. In addition, total serum cholesterol was associated with an increased risk of developing PDR (HR per 20 mg/dl 1.13, 95\% $\mathrm{Cl}$ 1.06-1.21), and serum HDL cholesterol reduced the risk of macular edema (HR per $10 \mathrm{mg} / \mathrm{dl}$ ). 0.83, 0.71-0.96). ${ }^{(14)}$ In this study, both groups' smoking history was not significant for the occurrence of diabetic retinopathy $(1.78 \pm 0.42$ vs. $1.78 \pm 0.42, p=$ 0.357). In another study, it was stated that the incidence of diabetic retinopathy was $66.6 \%$ in patients with a history of smoking and $47 \%$ in patients who did not smoke. The risk of developing diabetic retinopathy was 1.47 times in patients with a history of smoking ( $p>0.05) .{ }^{(13)}$ The mean physical activity in the diabetic retinopathy group was slightly lower than the non-diabetic retinopathy group, but this difference was not statistically significant (1.46 \pm 0.507 vs $1.61 \pm 0.49, p=0.255$ ). Another study mentioned that apolipoprotein A1 levels would increase after aerobic activity and was significant ( $p$
$<0.05)$. Likewise, the levels of apolipoprotein B also increased after aerobic activity $(p<0.05){ }^{(15)}$

In this study, HDL and triglyceride levels were not significantly different between the two groups, but the results were significantly different for LDL. This is in contrast to Amoorthy's study, which states that HDL levels are opposite to the severity of diabetic retinopathy, triglycerides are associated with an increased incidence and severity of diabetic retinopathy, but there was no significant difference in LDL and total cholesterol levels. ${ }^{(5,11)}$ Research by Namitha et al also states that there is a significant increase in total cholesterol, triglycerides, VLDL, and LDL in the group without diabetic retinopathy and a greater increase in the group with diabetic retinopathy compared to the healthy patient

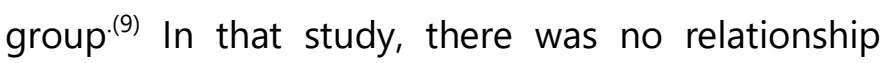
between serum lipids and the incidence and worsening of the severity of diabetic retinopathy. ${ }^{(16)}$ $\mathrm{HbA} 1 \mathrm{c}$ levels were also not significantly different in the two groups. These results differ from the results of the study by Garg et al., Where the severity of diabetic retinopathy is associated with $\mathrm{HbA} 1 \mathrm{c}$ levels and is significant. In another study, it was explained that severe diabetic retinopathy (including severe NPDR, PDR, and CME) was more common in patients with $\mathrm{HbA} 1 \mathrm{c}$ more than $10 \%{ }^{(17)}$ The study of Leske et al. stated that every increase in $\mathrm{HbA} 1 \mathrm{c}$ levels $1 \%$ from the baseline is associated with more than two times the risk of diabetic retinopathy. ${ }^{(18)}$

\section{CONCLUSIONS}

Apolipoprotein B levels were higher in the group with diabetic retinopathy than in the group without diabetic retinopathy and there were significant differences between the two. The limitations of this study are the small number of DME samples,so we cannot analyze the specifics. This study also did not include blood pressure as the variable studied so that the correlation between blood pressure and levels of apolipoprotein A1 and apolipoprotein B. In this study, we did not count the intensity of physical 
activity. Further research is needed with other research methods such as case-control studies or cohort studies to assess the causal relationship between elevated levels of Apo B and the incidence of diabetic retinopathy by calculating the ratio of apolipoprotein B to apolipoprotein A1.

\section{REFERENCES}

1. Amoorthy RKK, Kaliaperumal R, Achalam R, Poovitha R, Rajagopalan G. Apolipoproteins an early and better diagnostic marker for diabetic retinopathy. J Clin Diagnostic Res. 2017:

2. Nentwich MM. Diabetic Retinopathy - Ocular Complications of Diabetes Mellitus. World J Diabetes [Internet]. 2015;6(3):489.

3. Ramachandran A, Snehalatha C, Chan JCN, Chia KS, Shaw JE, Zimmet PZ. Diabetes in Asia and the Pacific: Implications for the Global Epidemic. Diabetes Care. 2016;39(March):472-85.

4. Sasongko MB, Wong TY, Nguyen TT, Kawasaki $R$, Jenkins $A$, Shaw J, et al. Serum apolipoprotein Al and B are stronger biomarkers of diabetic retinopathy than traditional lipids. Diabetes Care. 2011;

5. Prakash G, Agrawal R, Satsangi SK, Prakash S. Comparison of Serum Apolipoproteins and Traditional Lipids in Eyes with Diabetic Retinopathy in Indian Population: A Case Series. Middle East Afr J ophtalmol. 2016;23(2):212-4.

6. Ankit B, Mathur G, Agrawal R, Mathur K. Stronger relationship of serum apolipoprotein A-1 and B with diabetic retinopathy than traditional lipids. Indian J Endocr Metab [Internet]. 2017;21(1):102.

7. Chang YC, Wu WC. Dyslipidemia and Diabetic Retinopathy. Rev Diabet Stud. 2013;10(23):121-32.

8. Sasongko MB, Wong TY, Nguyen TT, Kawasaki $R$, Jenkins $A$, Shaw J, et al. Serum apolipoprotein $\mathrm{Al}$ and $\mathrm{B}$ are stronger biomarkers of diabetic retinopathy than traditional lipids. Diabetes Care. 2011;34(2):474-9.

9. Namitha $D$, Shilpashree, $A N, A R, N A R$. Apolipoprotein $\mathrm{A}-\mathrm{I}$ and Apolipoprotein $\mathrm{B}$ :
Better Indicators of Dyslipidemia in Diabetic Retinopathy Patients? Indian J Med Biochem. 2017;21(2):142-6.

10. Sharma Y, Saxena S, Mishra A, Saxena A, Natu SM. Apolipoprotein A-I and B and Subjective Global Assessment relationship can reflect lipid defects in diabetic retinopathy. Nutrition [Internet]. 2017;33:70-5.

11. Amoorthy RKK, Kaliaperumal $R$, Achalam $R$, Poovitha R, Rajagopalan G. Apolipoproteins an Early and Better Diagnostic Marker for Diabetic Retinopathy. J Clin Diagn Res. 2017;11(10):NC01-5.

12. Rasoulinejad SA, Hajian-Tilaki K, Mehdipour E. Associated factors of diabetic retinopathy in patients that referred to teaching hospitals in Babol. Casp J Intern Med. 2015;4(July):224-8.

13. Manaviat MR, Rashidi M. Four years incidence of diabetic retinopathy and effective factors on its progression in type II diabetes. Eur JOphtalmol. 2008;18(4):572-7.

14. Klein R, Klein BEK, Myers CE, Howard KP. Serum Lipids and Proliferative Diabetic Retinopathy and Macular Edema in Persons with Long Term Type 1 Diabetes: The Wisconsin Epidemiologic Study of Diabetic Retinopathy. JAMA Ophthalmol. 2016;133(5):503-10.

15. Yazdani R, Marefati H. Effect of Aerobic Exercises on Serum Levels of Apolipoprotein A1 and Apolipoprotein B, and Their Ratio in Patients with Chronic Obstructive Pulmonary Disease. Tanaffos. 2018;17(2):82-9.

16. Idiculla J, Nithyanandam S, Joseph M, Vk AM, Vasu U, Sadiq M. Serum lipids and diabetic retinopathy: A cross-sectional study. Indian J Endocr Metab. 2012;16:492-5.

17. Lokesh S, Shivaswamy S. Study of HbA1C levels in patients with type 2 diabetes mellitus in relation to diabetic retinopathy in Indian population. Int J adv Med. 2018;5(6):1397401.

18. Leske MC, WU SY, Hennis A, Hyman L. Hyperglycemia, Blood Pressure, and the 9Year Incidence of Diabetic Retinopathy. Ophtalmology. 2005;799-805.

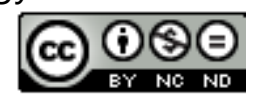

This work licensed under Creative Commons Attribution 